\title{
THICK FILM RESISTORS ON DIELECTRICS AS TEMPERATURE DETECTORS
}

\author{
BENEDYKT RZASA and JERZY POTENCKI
}

\author{
Technical University of Rzeszów, Institute of Automatics and Metrology, 39-959 Rzeszów, W. Pola str. No 2 \\ Poland
}

(Received August 15, 1984; in final form March 1, 1985)

\begin{abstract}
Thick film resistors made of typical ruthenate pastes on various dielectrics change their properties. The properties of such resistors, fabricated on the $\mathrm{TiO}_{2}+$ glass dielectric, have been evaluated in this paper. The usability of the structures of the type conductor-dielectric-resistor for the construction of temperature sensors has been determined. A practical solution for the temperature sensor, in the form of an RC network with distributed parameters, together with a circuit for the conversion of temperature into frequency has been presented.
\end{abstract}

\section{INTRODUCTION}

Thick film RC networks with distributed parameters $(\overline{\mathrm{RC}})$ are used most often for the realization of different types of active filters. The realization of an $\overline{\mathrm{RC}}$ with zero sensitivity of the time constant, $\mathrm{RC}$, to the change of the ambient temperature and with the $\mathrm{RC}$ value per network square unit kept as high as possible are basic problems relevant to the manufacturing of these types of active filters. ${ }^{1-3}$

A great many papers on thick film technology concern the production of $\overline{\mathrm{RC}}$ or multilayer circuits containing resistors. Such applications of thick films are characterized by printing of the typical resistor compositions on dielectric layers previously deposited on the alumina substrates. References ${ }^{4-8}$ spotlight numerous technological problems which occur in printing resistor pastes on the dielectric layers. It has been observed that the resistors manufactured on many dielectrics have different electrical properties from those made of the same materials on an alumina substrate. These properties depend upon the type of the resistor and the dielectric materials as well as the applied technology.

The effects of the dielectric type and firing conditions upon values of the resistance and the TCR(temperature coefficient of resistance) of ruthenate resistors made on the dielectric have been analysed in the paper by Rzasa and Potencki. ${ }^{9}$ A high sensitivity of these parameters several times higher than the change of technological conditions of fabricating layers has been found. Changes observed in the resistance values of resistors made on various dielectrics amounted to a few thousand per cent when comapred to the resistance values of those fabricated on an alumina substrate. Resistors made on the dielectric $\mathrm{TiO}_{2}+$ glass possessed high negative values of TCRs.

This paper presents an application of the change of properties of ruthenate resistors made on the dielectric $\mathrm{TiO}_{2}+$ glass to the realization of a temperature sensors. The result is a temperature-frequency converter made as an oscillator containing a temperature sensitive $\overline{\mathrm{RC}}$. 


\section{PROPERTIES OF RESISTORS MADE ON THE DIELECTRIC $\mathrm{TiO}_{2}$ + GLASS}

\subsection{Producing Test Samples}

A test pattern containing eight resistors, $3 \mathrm{~mm}$ long by $3 \mathrm{~mm}$ wide, arranged symmetrically on the alumina substrate $\left(96 \% \mathrm{Al}_{2} \mathrm{O}_{3}\right)$ was used for the investigation. The substrates with dimensions $20 \times 30 \times 0.65 \mathrm{~mm}$ were selected according to their thickness with an accuracy of $\pm 0.01 \mathrm{~mm}$. The $\mathrm{TiO}_{2}+$ glass dielectric paste was printed three times on the whole surface of the substrate through a steel screen of the density of 6400 openings $/ \mathrm{cm}^{2}$ (200 mesh). A series of dielectric pastes was used, for which the content of the $\mathrm{TiO}_{2}$ in the constant constituent was a parameter and changed from $30 \%$ to $90 \%$ of the volume. After each printing the layer was dried for 30 minutes at a temperature of $120^{\circ} \mathrm{C}$. The firing of the dielectric was carried out in a four-zone tunnel furnace with a movable conveyor and trapezoidal temperature distribution along the length of the furnace. Speed control of the conveyor moving in the direction opposite to the laminar air flux flowing through the furnace made it possible to change the time of temperature increase, the time at peak and the time of temperature decrease. The parameters of firing were as follows:- the time of firing - 45 minutes; the peak firing temperature $850^{\circ} \mathrm{C}$; the time at peak temperature -15 minutes. The thickness of dielectric layer after firing was about $60 \mu \mathrm{m}$.

Patterns of the conductive contacts, made of platinum-gold paste DP 8351 or palladium-silver paste DP 8151 , were printed on the fired dielectric layer. The printed patterns were dried as before and fired at peak firing temperature of $850^{\circ} \mathrm{C}$ for about 10 minutes. Then resistor paste DP series 1400 was printed thorugh a steel screen of density of 10000 openings $/ \mathrm{cm}^{2}$ (250 mesh). Bismuth ruthenate $\mathrm{Bi}_{2} \mathrm{Ru}_{2} \mathrm{O}_{7}$ was the conductive constituent of the resistor pastes. The bismuth ruthenate quantity in the paste deterimined its resistivity. The resistivity of the pastes which were used was $10 \Omega / \square, 1 \mathrm{k} \Omega / \square, 10 \mathrm{k} \Omega / \square$, and $100 \mathrm{k} \Omega / \square$. Drying conditions were the same as for the dielectric and conductive pastes. The parameters of firing resistive layers were as follows:- the total firing time-60 minutes; peak firing temperature changed in the range $760^{\circ} \mathrm{C}$ to $860^{\circ} \mathrm{C}$; the time at peak temperature -15 minutes. The thickness of the resistor layers after firing varied from 12 to $15 \mu \mathrm{m}$.

The surface of the resistors and its nearest surroundings were covered with a protective layer of DP 8185 glass. The encapsulated glass was printed twice through a steel screen of the density of 6400 openings $/ \mathrm{cm}^{2}$ (200 mesh), and the dried layer was fired at peak temperature of $550^{\circ} \mathrm{C}$ for about 10 minutes.

\subsection{Temperature characteristic of the resistance}

Negative values of the temperature coefficient of resistance at low temperatures and positive values of the TCR at higher temperatures are typical dependences of the resistance upon temperature of resistive thick films. Such characteristics can be observed for Pol- $\mathrm{Ag}$ resistive layers and ruthenate resistive layers produced on alumina substrate. Minimum resistance generally occurs in the proximity of room temperature. In the range of ambient temperature actually used the TCR values of resistors are within the range $0 \pm 300 \mathrm{ppm} /{ }^{\circ} \mathrm{C}$.

The temperature dependence of the resistivity for the ruthenate resistors produced on the $\mathrm{TiO}_{2}+$ glass dielectric is completely different. In the range of ambient temperatures from $-60^{\circ} \mathrm{C}$ to $+125^{\circ} \mathrm{C}$ the resistance decreases linearly as the temperature increases. A typical progression of the resistance changes as a function of the ambient temperature for these resistors is shown in Figure 1. Maximum deviations of measuring points from the straight line do not exceed $\pm 1.3 \%$ in the measured temperature range. It is best to approximate the characteristics in Figure 1 by two 


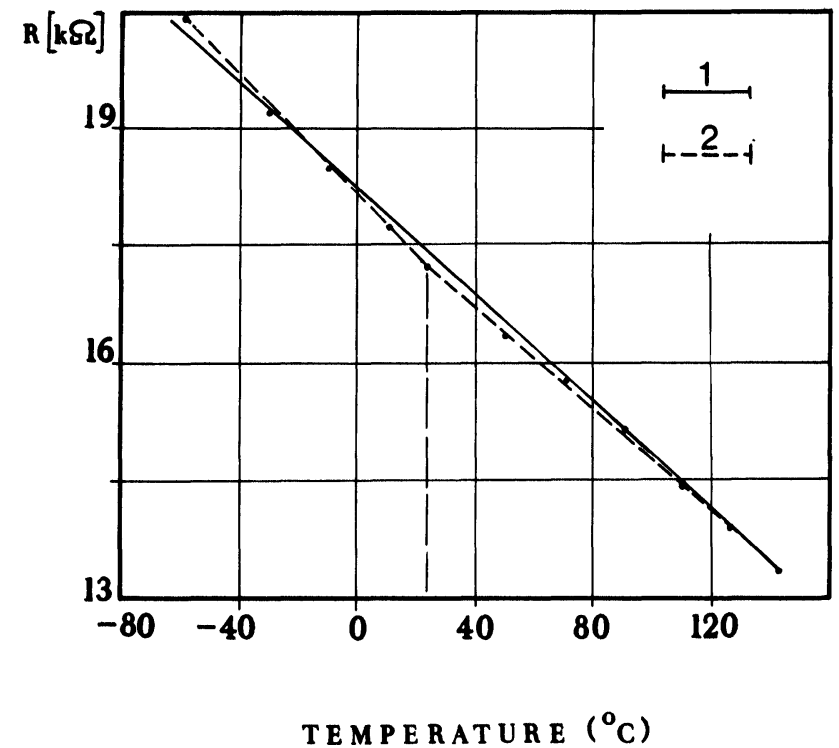

FIGURE 1 Temperature characteristic of ruthenate resistors made of $1 \mathrm{k} \Omega / \square$ resistive paste on dielectric $70 \% \mathrm{TiO}_{2}+30 \%$ glass; $\cdots$ - experimental points, - - - - approximation by one straight line, - - - approximation by two straight line segments.

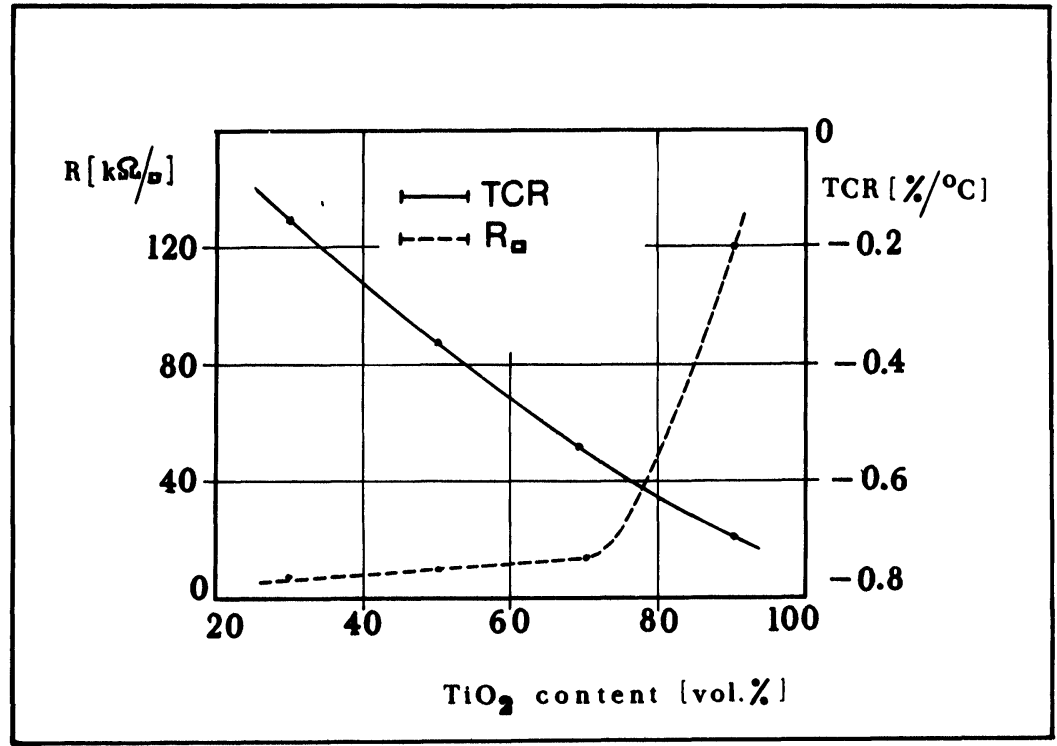

FIGURE 2 Effect of $\mathrm{TiO}_{2}$ content in dielectric on resistance and TCR of resistors made of $1 \mathrm{k} \Omega / \sqcup$ paste. Resistor peak firing temperature $830^{\circ} \mathrm{C}$. 
segments of a straight line which converge at the temperature of $25^{\circ} \mathrm{C}$ and hence determining the hot and cold TCR from the definition:-

“Hot" TCR $=\frac{\mathrm{R}_{125}-\mathrm{R}_{25}}{\mathrm{R}_{25}} \times \frac{10^{6}}{100}\left[\mathrm{ppm} /{ }^{\circ} \mathrm{C}\right]$

“Cold" TCR $=\frac{\mathrm{R}_{25}-\mathrm{R}_{-55}}{\mathrm{R}_{25}} \times \frac{10^{6}}{80}\left[\mathrm{ppm} /{ }^{\circ} \mathrm{C}\right]$

The calculated TCR values for the measured characteristic are negative and amount to $-0.17 \% /{ }^{\circ} \mathrm{C}$ and $-0.21 \% /{ }^{\circ} \mathrm{C}$ for the hot and cold TCR, respectively. Maximum deviations of measuring points from linearity in the range of negative and positive temperatures are smaller than $\pm 0.6 \%$.

2.3 Effect of the $\mathrm{TiO}_{2}$ Concentration in the Dielectric and Resistivity of Ruthenate Pastes Upon the Basic Parameters of Resistors

Measurements were made of the resistance value of resistors made on $\mathrm{TiO}_{2}+$ glass dielectric at room temperature and of resistance changes in the temperature function from $25^{\circ} \mathrm{C}$ to $125^{\circ} \mathrm{C}$. Resistance values at room temperature were averaged from the results of 16 independent measurements. The effect of ambient temperature on the resistance value of the resistors was evaluated by determining the hot TCR.

It can be observed that the sheet resistivity of the ruthenate layer made on the $\mathrm{TiO}_{2}+$ glass dielectric increases several times when compared to the paste resistivity, for all investigated pastes (Figure 2). The resistance of the layers generally increase together

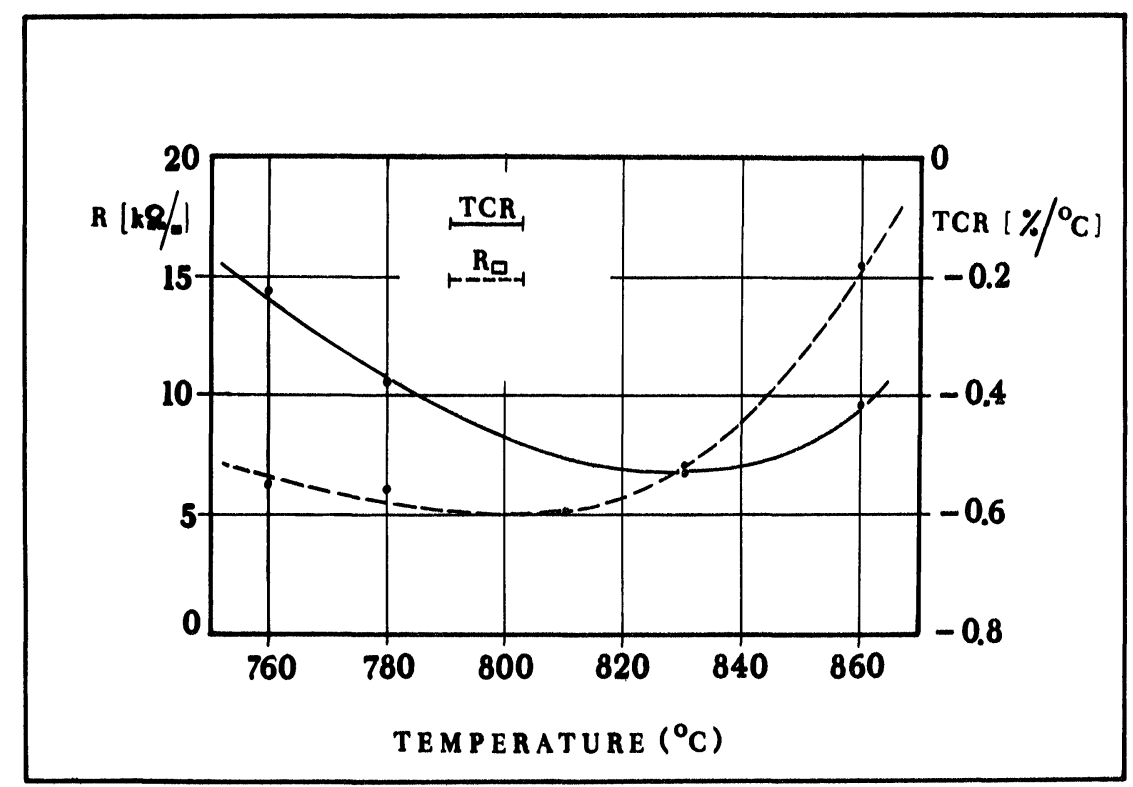

FIGURE 3 Effect of resistor peak firing temperature on resistance value and TCR. Resistors made of $1 \mathrm{k} \Omega / \square$ paste on dielectric $70 \% \mathrm{TiO}_{2}+30 \%$ glass. 
TABLE I

Effect of paste sheet resistivity on resistance and TCR of resistors made on $90 \% \mathrm{TiO}_{2}+10 \%$ glass dielectric

\begin{tabular}{lcccc}
\hline Sheet resistivity of paste & & & & \\
{$[\mathrm{k} \Omega / \square]$} & 0.01 & 1 & 10 & 100 \\
$\mathrm{R}_{\square}[\mathrm{k} \Omega / \square]$ & 0.026 & 120 & 810 & 2200 \\
$\mathrm{TCR}\left[\% /{ }^{\circ} \mathrm{C}\right]$ & -0.063 & -0.69 & -0.52 & -0.48 \\
\hline
\end{tabular}

with an increase of the $\mathrm{TiO}_{2}$ concentration in the dielectric. Layers made on the $90 \%$ $\mathrm{TiO}_{2}+10 \%$ glass dielectric showed expecially large resistance increases. The TCR of these layers is highly negative and decreases as linearly as the $\mathrm{TiO}_{2}$ concentration in the dielectric increases. The resistance and TCR changes of layers made from other pastes of DP 1400 series have a similar nature.

Peak firing temperature of resistor pastes DP 1400 series has an effect on the $R_{\square}$ value and the TCR manufactured layers. Typical results are shown in Figure 3 and Table I. The highest absolute values of the TCR's are obtained for resistors fired in the range of peak temperatures from $830^{\circ} \mathrm{C}$ to $850^{\circ} \mathrm{C}$.

\subsection{Resistance Reproducibility of Resistors Made on the $\mathrm{TiO}_{2}$ " glass dielectric}

In the process of manufacturing resistors there occur some factors which restrict the precision of reproducing resistance values. These factors comprise the geometry of the layers, the properties of pastes, the parameters of printing and the firing process. Changes of geometry of the produced resistive layer (linear sizes and the layer thickness) and the resistivity changes will be the result of the effect of these factors.

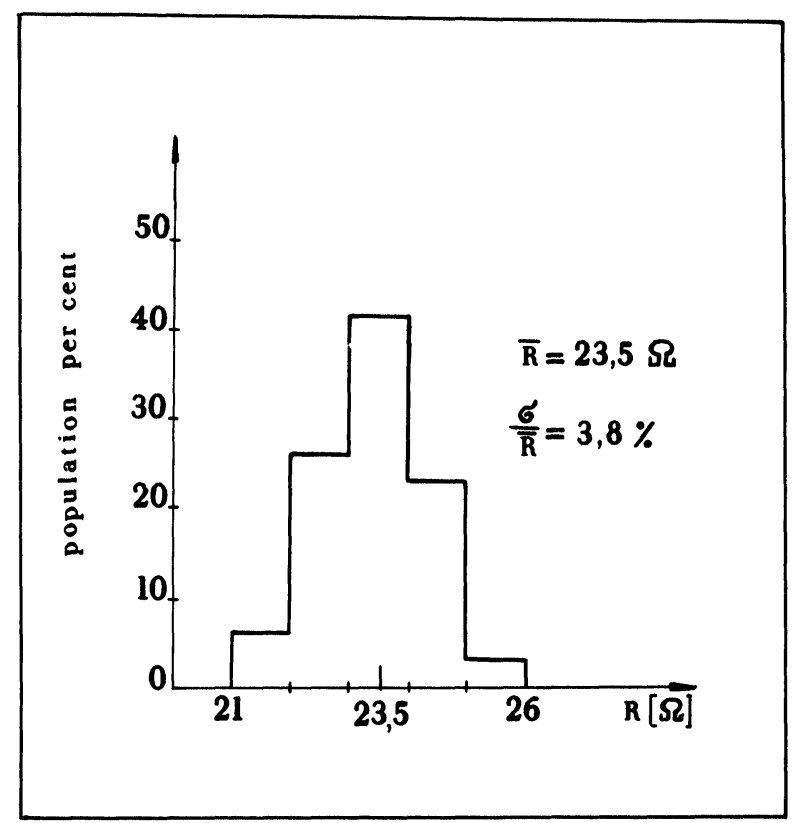

FIGURE 4 Resistance histogram of resistors made of $10 \Omega / \square$ paste on $70 \% \mathrm{TiO}_{2}+30 \%$ glass dielectric Firing temperature $830^{\circ} \mathrm{C}$. 
Their total effect on the resistance value of resistors may be expressed by determining its mean value $(\bar{R})$ and the spread of resistance values $(3 \sigma / \bar{R})$. The results of the resistance measurements within a batch of 30 resistors are illustrated in the form of the histogram in Figure 4. The spread of resistance values as well as the relative maximum deviation from the average are inconsiderable and amount to:-

$\frac{3 \sigma}{\overline{\mathrm{R}}}=11.4 \% ; \frac{\mathrm{R}_{\max }-\overline{\mathrm{R}}}{\overline{\mathrm{R}}}=7.1 \% ; \frac{\mathrm{R}_{\min }-\overline{\mathrm{R}}}{\overline{\mathrm{R}}}=-8 \% ;$ respectively

The spreads of resistance values within other batches of resistors were smaller than $\pm 20 \%$ and were independent of the dielectric type and conductive contacts, the resistivity of applied pastes and the conditions of the firing process of layers.

The resistance values of resistors made on the dielectric layer may be trimmed by removing a part of the resistor with a flux of abrasive sand. The tests which were carried out made it possible to decrease the spread of resistance values within a batch of resistors to $\pm 2 \%$. The TCR value of the trimmed resistors remained unchanged.

\subsection{Effect of Accelerated Ageing on the Resistance Value and the TCR of Resistors}

Resistors made on the dielectric $\mathrm{TiO}_{2}+$ glass were submitted to accelerated ageing at an ambient temperature of $150^{\circ} \mathrm{C}$ for a period of 1000 hours. The smallest batch size was 30 resistors. All the resistors were protected against the effect of moisture with a protective coating made of DP 8185 glass. Average relative changes of resistance $(\overline{\Delta \mathrm{R}} / \overrightarrow{\mathrm{R}})$ and the TCR value were determined after 100, 200, 500, 700 and 1000 hours of ageing.

An increase of resistance with time during ageing occurs in all cases. The greatest resistance changes occur during the first 200 hours of ageing (Figure 5) and amount to $10 \%$ for resistors made on the $70 \% \mathrm{TiO}_{2}+30 \%$ glass or $90 \% \mathrm{TiO}_{2}+10 \%$ glass dielectric. During the next period of ageing the resistance values stabilize at a level dependent

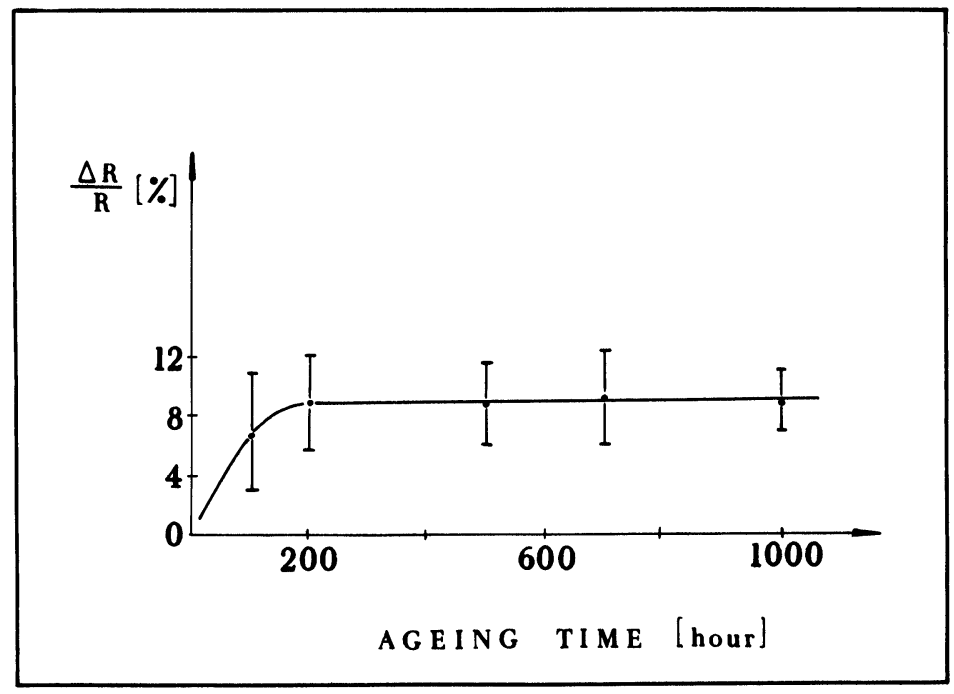

FIGURE 5 Resistance relative change of resistors aged at an ambient temperature of $150^{\circ} \mathrm{C}$. Resistors made of $1 \mathrm{k} \Omega / \square$ paste on dielectric $70 \% \mathrm{TiO}_{2}+30 \%$ glass. Firing temperature $860^{\circ} \mathrm{C}$ 
TABLE II

Resistance percentage change of resistors made of $1 \mathrm{k} \Omega / \square$ paste on $\mathrm{TiO}_{2}+$ glass dielectric after 1000 hours of ageing at an ambient temperature of $150^{\circ} \mathrm{C}$

\begin{tabular}{|c|c|c|c|c|c|}
\hline type of dielectric & 760 & 790 & 810 & 830 & 860 \\
\hline $50 \% \mathrm{TiO}_{2}+50 \%$ glass & 6.3 & 6.0 & 7.6 & 7.3 & 7.2 \\
\hline $70 \% \mathrm{TiO}_{2}+30 \%$ glass & 8.7 & 7.4 & 6.5 & 8.2 & 9.1 \\
\hline $90 \% \mathrm{TiO}_{2}+10 \%$ glass & 12.6 & 12.1 & 10.2 & 9.2 & 8.7 \\
\hline
\end{tabular}

Resistance relative change with plus sign

upon the $\mathrm{TiO}_{2}$ content in the dielectric and the conditions of firing the resistors (Table II). Maximum deviations of the relative changes of resistance from the mean value determined by the confidence interval $3 \sigma$ were smaller than $\pm 5 \%$.

During the first period of ageing of the resistors (200 hours) there also occurs a decrease of the TCR values. Later, however, the TCR values become stable, about $15 \%$ smaller than the TCR before ageing.

Adjusting the resistance value of resistors, which were submitted to preliminary ageing for 1000 hours at a temperature of $150^{\circ} \mathrm{C}$, does not make the stability of resistance worse during the later period of ageing. Relative resistance changes of resistors after the adjustment were smaller than $\pm 1 \%$ during a 1000 hours period of ageing at a temperature of $150^{\circ} \mathrm{C}$ provided that the resistor regions uncovered during the trimming were protected again with a glass layer.

\section{PRACTICAL REALIZATION OF THE TEMPERATURE SENSOR}

Thermistors manufactured by means of thick film technology have a negative TCR whose value varies from some fractions of a per cent to a few per cent for each degree Celsius. ${ }^{10}$ The resistance of thermistors decreases exponentially as the temperature increases. Ruthenate resistors made on the dielectric $\mathrm{TiO}_{2}+$ glass dielectric, whose resistance also decreases with the temperature increase and whose TCR values are obtained in the interval -0.1 to $-0.7 \% /{ }^{\circ} \mathrm{C}$, can be successfully used as substitutes for typical thermistors in circuits for temperature measurement. The advantage of the latter are linear temperature characteristics in the interval of -55 to $+125^{\circ} \mathrm{C}$. High resistance values of these resistors can be reduced considerably by increasing the thickness and decreasing the length/width ratio of the printed resistor layers. The application of the ruthenate resistors made on the dielectric $\mathrm{TiO}_{2}+$ glass as temperature sensors is conditioned by carrying out a preliminary ageing of resistors in order to stabilize their parameters.

The sensors were made in the form of RC networks with distributed parameters which consists of three layers: conductive, dielectric and resistor ones deposited one after the other (Figure 6). The conductive and resistor layers, separated from each other by the dielectric layer, form the distributed capacity and the distributed resistance is formed by the upper resistor layer. The $\overline{\mathrm{RC}}$ for which parameters have been presented was made of the following materials:- the conductive layer and the contacts - of platinum-gold paste DP 8351; dielectric layer- of $\mathrm{TiO}_{2}+$ glass paste; the resistor layerof ruthenate paste DP 1431 . The $\overrightarrow{R C}$ is integrated with the alumina substrate and its surface is covered with a protective layer made of DP 8185 glass. The authors experimented with other conductive materials on the base $\mathrm{Pd}-\mathrm{Ag}$ and $\mathrm{Au}$ and they obtained similar results. 


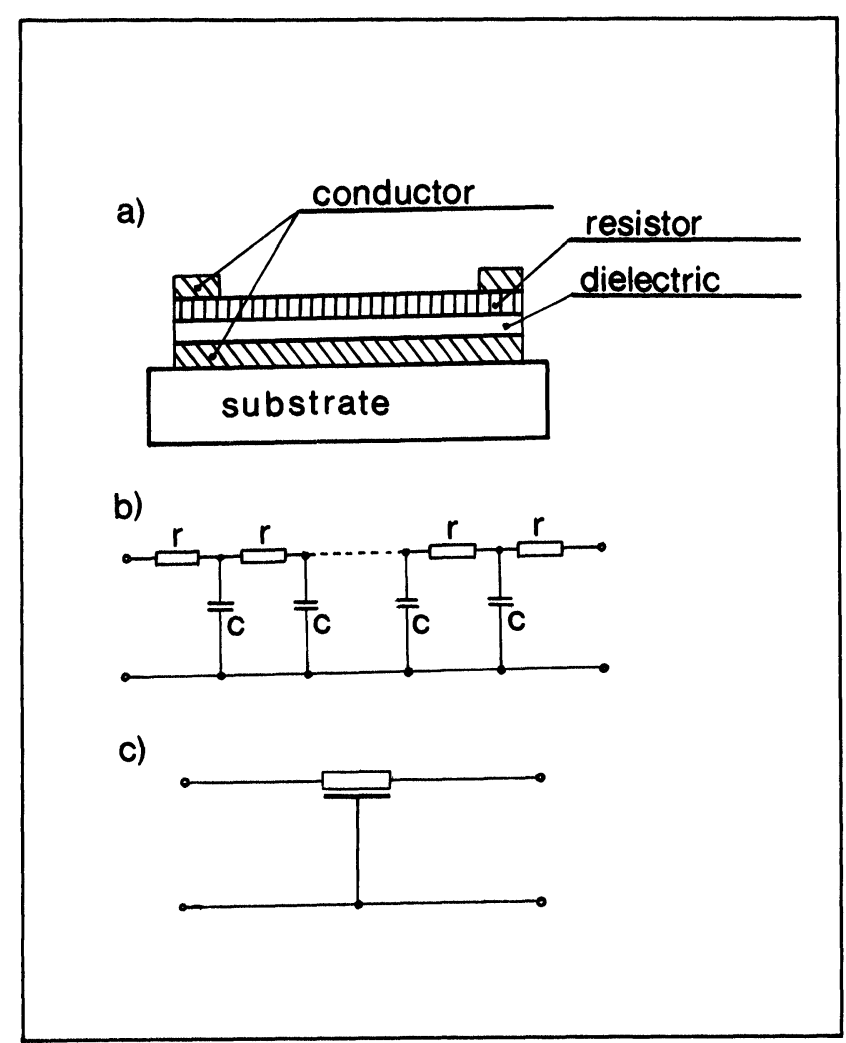

FIGURE 6 RC network with distributed parameters:- a) layer model, b) electrical equivalent circuit, c) electrical equivalent, $r, c$ - shect resistance and capacitance respectively of $\overline{R C}$

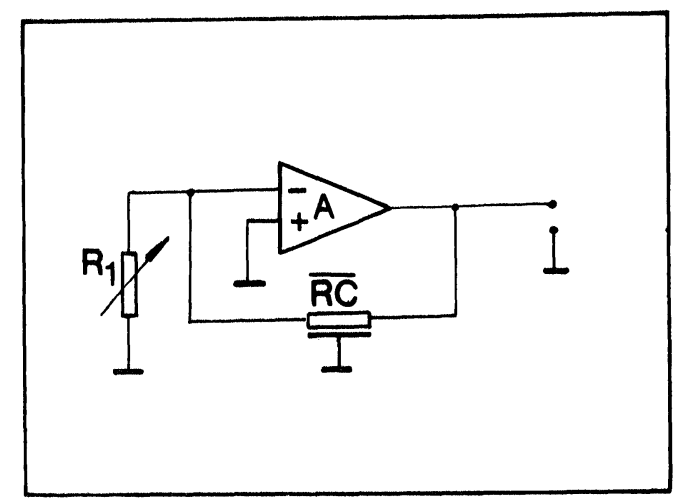

FIGURE 7 Electrical circuit of oscillator circuit with $\overline{\mathrm{RC}}$. 
The temperature coefficient of capacity (TCC) in such an $\overline{\mathrm{RC}}$ is negative and can be changed between $0 \% /{ }^{\circ} \mathrm{C}$ to $-0.07 \% /{ }^{\circ} \mathrm{C}$ by changing the $\mathrm{TiO}_{2}$ concentration in the dielectric (Rzasa, References 11). The temperature coefficient of resistance is also negative (chapter 2 properties of resistors made on the dielectric $\mathrm{TiO}_{2}+$ glass). The temperature coefficient of the time constant of $\overrightarrow{\mathrm{RC}}$ :

$\frac{\Delta(\mathrm{RC})}{\mathrm{RC}} \cdot \frac{1}{\Delta \mathrm{T}}=\mathrm{TCC}+\mathrm{TCR}$

will be negative and may be adjusted between $-0.06 \% /{ }^{\circ} \mathrm{C}$ and $-0.75 \% /{ }^{\circ} \mathrm{C}$.

A circuit with the characteristic of a lowpass filter is the basic configuration of the $\overline{\mathrm{RC}}$. The amplitude-phase characteristic of the transfer function of this filter crosses the origin of the coordinates, which ensures that at a defined frequency its angle of phase shift assumes the value equal to $-\pi$. If the $\overline{\mathrm{RC}}$ in a low-pass filter configuration is placed in the feedback path of an amplifier (Figure 7), the circuit becomes an oscillator. The formation of vibration in the circuit is conditioned by:-

$\mathrm{K}_{0}(j \omega) \cdot \mathrm{K}(j \omega) \geqslant 1$

where

$\mathrm{K}_{0}(j \omega)$ - voltage amplification of the amplifier;

$\mathbf{K}(j \omega)$ - voltage transfer function of the $\overline{R C}$;

The generated frequency dependence $\mathrm{f}$, is:-

$\mathrm{f}=\frac{\pi}{\mathrm{RC}}$

and the expression of the minimum voltage value indispensable to the vibration formation is given by:-

$$
\left|\mathrm{K}_{0}(\mathrm{j} \omega)\right| \geqslant[\cosh \pi] \cdot[\cos \pi] \approx 11.57
$$

This is obtained as the solution of equation (4).

According to expression (5) the change of the $\overline{\mathrm{RC}}$ resistance and capacity under the effect of the temperature causes a change of generated frequency. Expression (5) is true on the assumption that the angle of phase shift of the amplifier is close to the value ${ }^{\pi}$ and that the input resistance of the amplifier loads the $\overline{\mathrm{RC}}$ to a very small degree.

After the preliminary period of ageing, 500 hours at the temperature of $150^{\circ} \mathrm{C}$, the parameters of the $\overline{\mathrm{RC}}$ used in the oscillator were as follows: $\mathrm{R}=264.72 \mathrm{k} \Omega ; \mathrm{C}=684 \mathrm{pF}$; $\mathrm{TCR}=-0.386 \% /{ }^{\circ} \mathrm{C} ; \mathrm{TCC}=-0.014 \% /{ }^{\circ} \mathrm{C}$. An operational amplifier type ULY 7741 was used. The frequency of the $f$ signal at the oscillator output is a linear function of the $\overline{R C}$ ambient temperature (as shown in Figure 8). The resistor $R_{1}$ (Figure 6) makes it possible to adjust the circuit amplification coefficient and to change the inclination of the straight lines of frequency vs. ambient temperature.

The ageing changes of the resistance and the capacitance of the $\overline{R C}$ line have a decisive effect on the long term stability of the frequency of the converter output signal. The stability of this signal has been better than $\pm 1 \%$ during 1000 hours of ageing at a temperature of $150^{\circ} \mathrm{C}$, if one leaves out of account the initial period.

$\mathrm{A}$ uniform $\overline{\mathrm{RC}}$ was made use of in the oscillator circuit. It was also checked that application of the exponentially tapered $\overline{\mathrm{RC}}$ in the circuit makes possible the reduction 


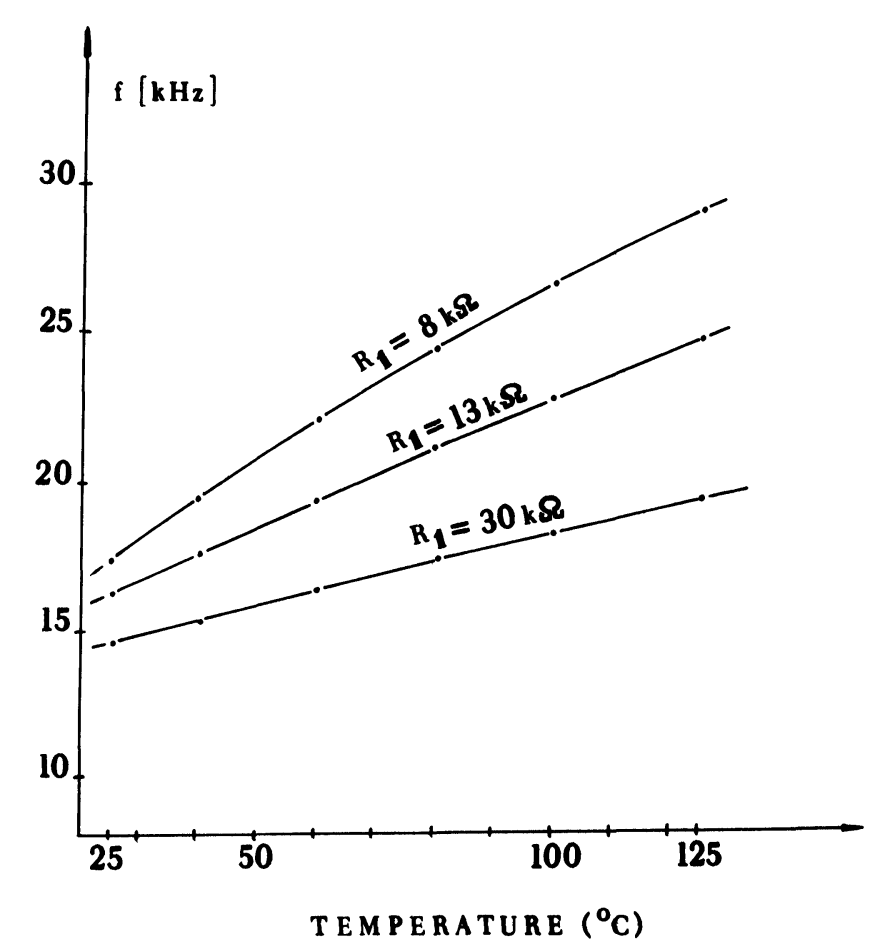

FIGURE 8 Frequency change as function of ambient temperature.

of the minimum amplification value of the amplifier, indispensable to fulfilling the amplitude condition of the oscillator. This leads to the reduction of the signal losses in the feedback path which makes the oscillator operation possible with a lower supply current.

\section{CONCLUSION}

The resistance of ruthenate resistors made on the dielectric $\mathrm{TiO}_{2}+$ glass decreases linearly as the temperature increases. In the temperature range from $25^{\circ} \mathrm{C}$ to $125^{\circ} \mathrm{C}$ the temperature coefficient of resistance of these resistors assumes values in the interval 0.06 to $-0.7 \% /{ }^{\circ} \mathrm{C}$ according to the type of materials used and the applied parameters of the technological process. Ruthenate resistors made on the dielectric $\mathrm{TiO}_{2}+$ glass may be utilized for temperature measurements and for compensation of the electric circuits characterized by a positive coefficient of the resistance. The realization of $\mathrm{RC}$ with high negative temperature coefficient of the time constant is practical for a temperature sensor. A simple circuit of a converter from temperature to frequency provides the linear dependence of the output signal as a temperature function. Such a circuit is insensitive to external interference. 


\section{REFERENCES}

1. J. Rapeli, 'Distributed RC filters in thick and thin film techniques', Elektronika, 2 pp. 7-12 (1984) (in English).

2. P.K. Majithia, P.L. Moran, A.J. Walton, N.G. Burrow, The thick film realisation of distributed-lumpedactive filters' ISHM '78 International Symposium on Microelectronics, Minneapolis, Minnesota, pp. 321-326 (1978).

3. P.L. Moran, J. Butler, 'A stable thick film resistor capacitor with audio time constants'. Material Matters, ESL. Inc., III, No 4 (1983).

4. J.A. Hain, 'High voltage stable resistor on multilayer dielectric', Solid State Technology, pp. 102-105 (October 1979)

5. K.E. Pitt, B. Joski, E.A. Winster, 'The properties of thick film resistors on dielectrics'. Microelectronics Journal, pp. 4-11, (September/October, 1982).

6. R. Ostwald, A.F. Bogenschutz, 'Compatibility of thick film resistors on glass ceramic layers', Ber. Dtsch. Keram. Ges 53, No 2, pp. 55-58, (in German).

7. N. Sugishita, A Ikegami, T. Ende, 'Processing considerations of thick film devices with multilayered resistors'. Electrocomponent Science and Technology, 9, pp. 59-65, (1981).

8. J. Taitl, 'Thermal expansion and laser trim stability of ruthenium based thick film resistors on alumina and on multilayer dielectric'. Hybrid Circuits, 1, (Autumn 1982).

9. B. Rzasa, J. Potencki, 'The properties of thick film resistors fabricated on various dielectric layers'. Hybrid Circuits, 5, pp. 25-28, (Autumn 1984).

10. O.A. Short, 'Thermistor compositions and thermistors made therefrom' Patent USA no 3.408 .311 (1966).

11. B. Rzasa,'Technology of thick film rutile capacitors'. Qualifying thesis, Technical University of Rzeszów, (1980), (in Polish). 

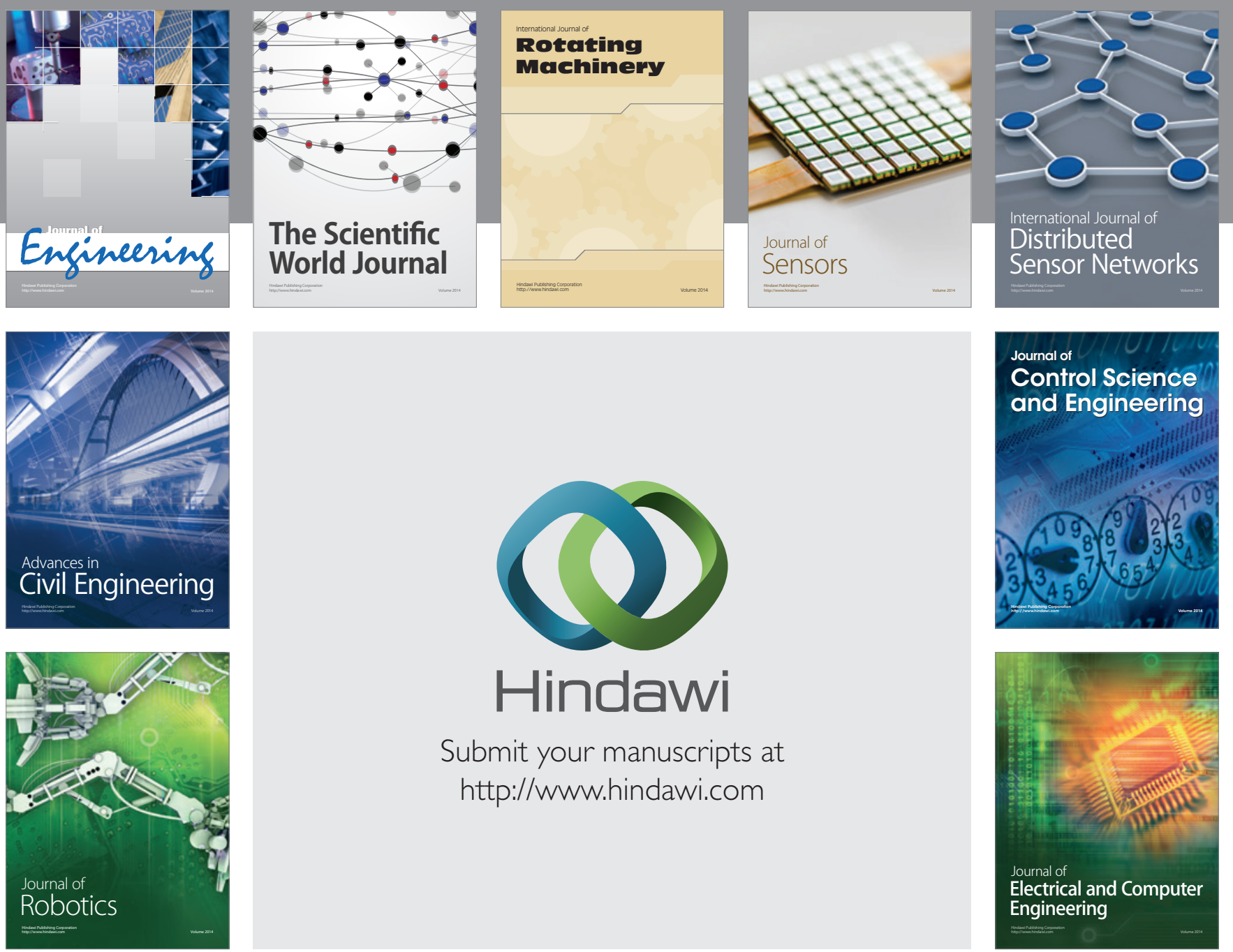

Submit your manuscripts at

http://www.hindawi.com
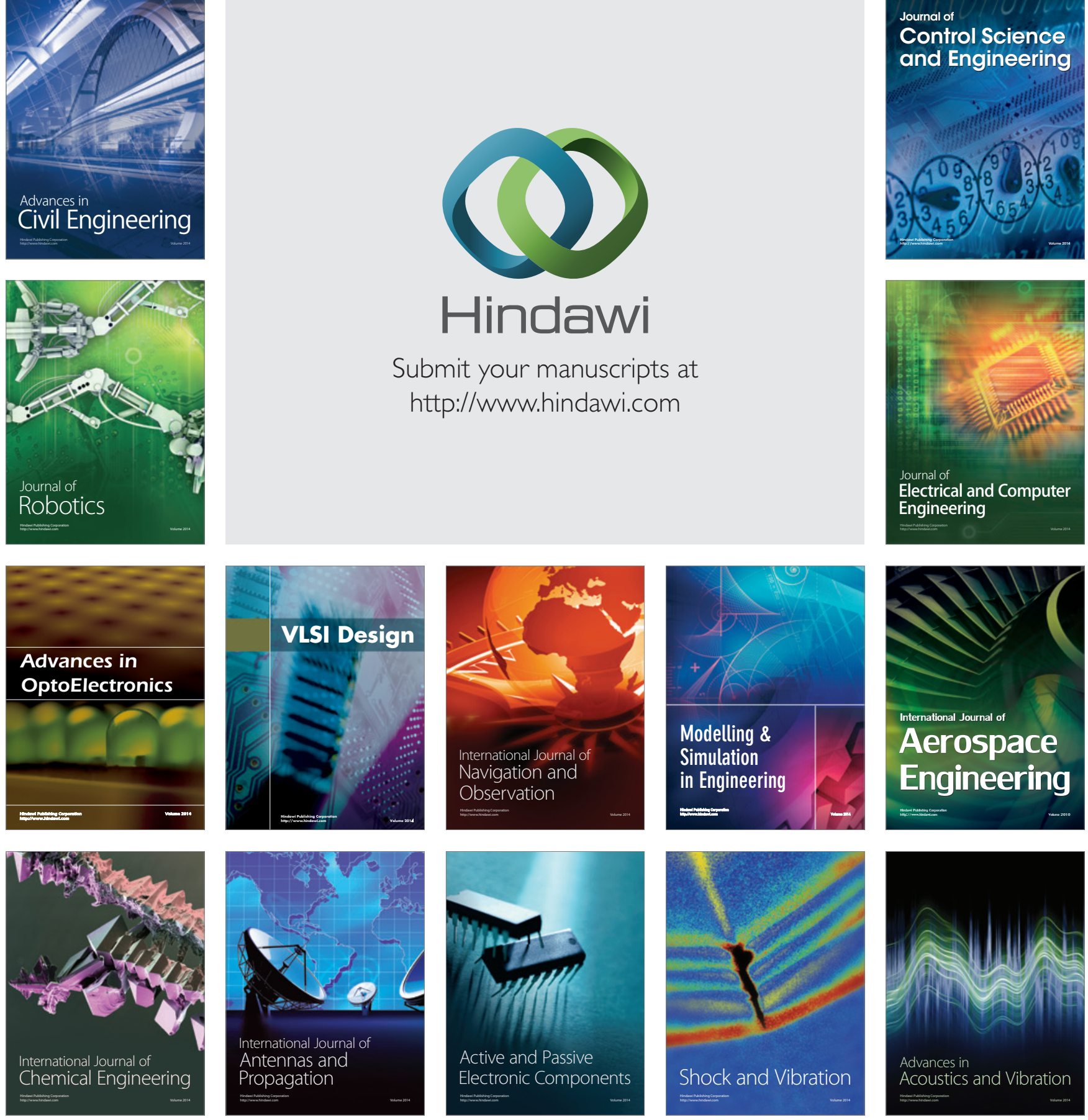